\title{
Manufacturing FX 63-137 Aerofoil by using CNC Machine and determine Aerodynamic Characteristic for this Aerofoil
}

\author{
MAGEDI MOH. M. SAAD, NORZELAWATI BINTI ISMAIL \\ Faculty of Mechanical Engineering, University Tun Hussein Onn, Malaysia \\ E-mail address: Magedi983@yahoo.com, norzela@uthm.edu.my
}

Keywords: Wind Tunnel; lift: Drag; angle of attack

\begin{abstract}
The aim of this paper is to manufacturing and testing FX 63-137 aerofoil at different speed by using experimental wind tunnel, and select best angel of attack. This paper uses an approach in which the process is divided into many steps. Firstly, manufacturing aerofoil by using CNC Machine. Secondly, testing the aerofoil by using Wind Tunnel, Finally display and compare results with another reference results with to evaluate the solutions are studied and the up-scaling rule which is a way to get some general insight for this aerofoil.
\end{abstract}

\section{INTRODUCTION}

Aerofoil play essential part to develop lift and getting best performance in aircraft or turbines.

Design of an airfoil structure with the curved surface is to give the most favorable ratio of lift and drag. Much research, experiments have occurred on the most specific characteristics of the aerofoil, with the objectives of better lift, higher performance, and higher endurance. [1]

The most optimal characteristics of the aerofoil will be calculated using Wind tunnel, and then display the results a practical experiment, these results can be used to check how an accurate the simulations are and how these characteristics can contribute to better lift and endurance.

\section{A. Airflow around the aerofoil}

At a small angle of attack, stagnation point is the point at which the particles of air slowing down and which they is divided into two is the point at which they slowdown in air particles, which are divided into two parts of surface. Figure 2.2 shows the streamline division produces from increase in velocity at the upper surface while at the lower surface the velocity will decrease [2]

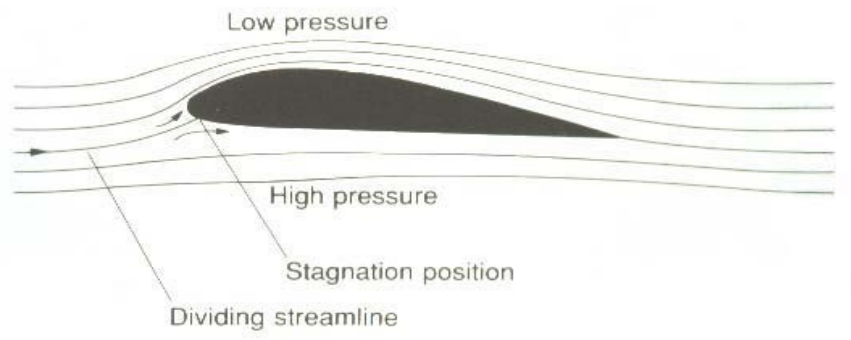

Streamlines around 2D airfoil

The flow separation produced due to the friction. At the leading edge the flow accelerates to the upper surface and decreased at lower surface this will be higher pressure at upper surface more than lower surface the pressure is decreased to a minimum value, which is below the static pressure. As the flow is near the trailing edge.[3] 
The rate of increase in pressure is rapid occur when the flow moves near the trailing edge. When increases the angle of attack at the leading edge the pressure drops to a value far below the free stream static pressure. The cause stalling occurred when the flow field tends to separate from the surface.

\section{B. Wing design}

The Aerofoil data at low Reynolds number from seldom get it. However would be found aerofoil performance at low Reynolds numbers for aerofoil (FX 63-137). For maximum endurance must obtain the best design for the wing because he is one of the fundamental factors and the essential for that.

We chose FX 63-137 because it is superior in aerodynamics characteristics at low Reynolds number and at Low Speed. This aerofoil has characteristic high lift coefficient where reach about 1.6, this property not found in other airfoils. Figure 2.4 shows the FX 63-137 aerofoil.

\section{MANUDACTURING AIRFOIL (FX63-137)}

First, these are the steps that were carried out in the CNC machine is VERTICAL CENTER NEXUS 410A-II (MATRIX CAM) workshop of the UTHM University to manufacture the FX 63137 wing, which will be tested with subsonic wind tunnel for the aerodynamic characteristics:

- Create AutoCAD file version 2007 and exported to the machine program.

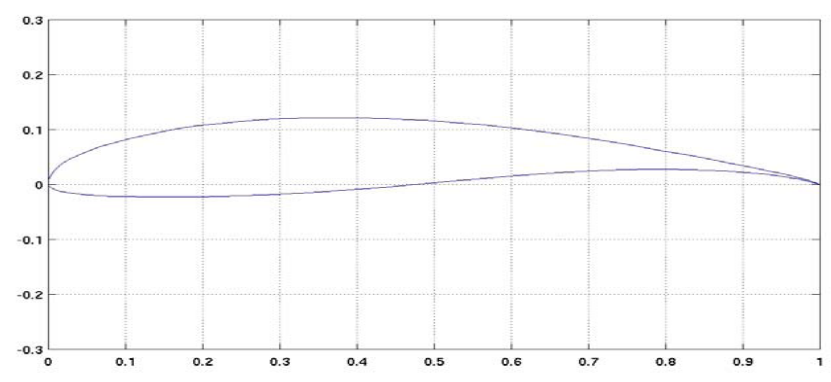

Select chain command to connect points together[4]

- $\quad$ Select Set and Program Edit to check form final shape.

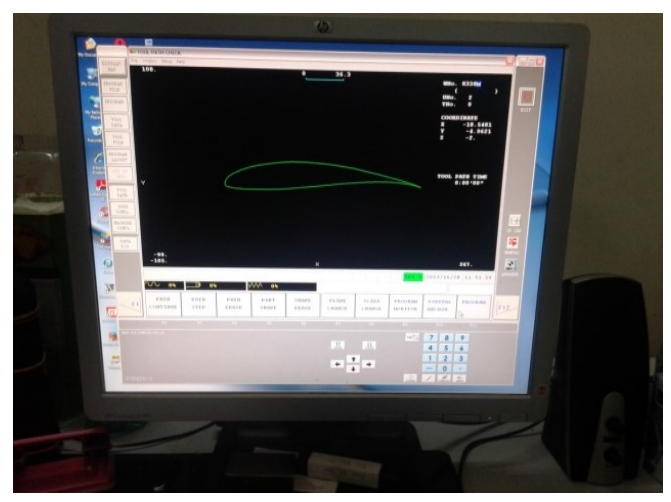

Prepare machine to work 
- After the completion of manufacturing pieces airfoil as shown.

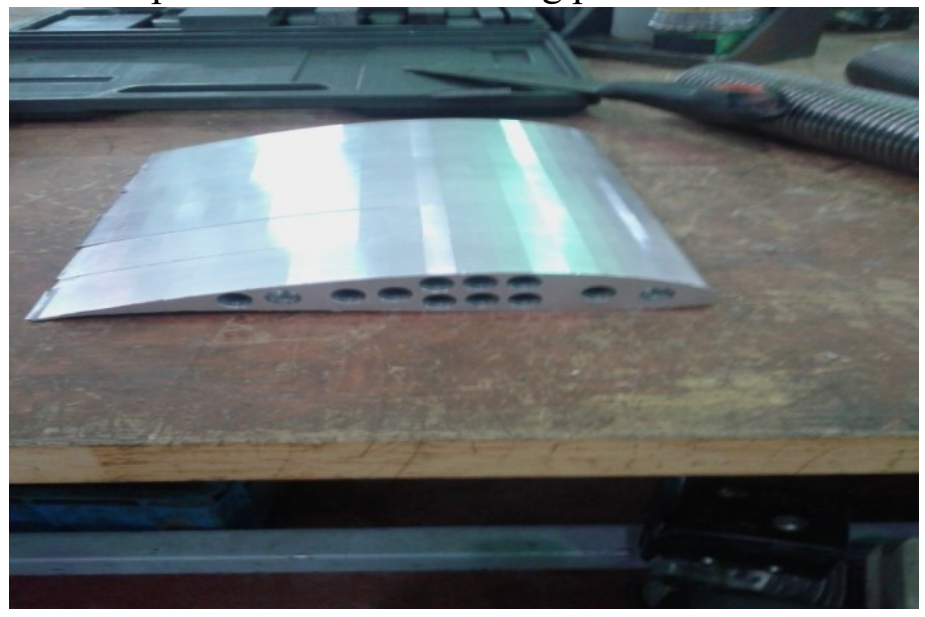

Final shape of aerofoil before fixated together

- After prepare slot at quart airfoil with diameter $1.1 \mathrm{Cm}$ prepare rod with same diameter and with length $67.3 \mathrm{Cm}(45 \mathrm{~cm}$ inside aerofoil).

- Passes the rod inside the aerofoil to connect all pieces together and to fix the rod in the aerofoil

\section{TESTING THE WING WITH SUBSONIC WIND TUNNEL.}

A. wind tunnel body.

The Subsonic Tunnel is used to conduct the experiments to evaluate the aerodynamic characteristics FX63-137. The apparatus is dispatched, as shown in Figure 4.7, in four main pieces:

- The Main Frame.

- The Silencer

- The Effuser Cone.

- The Control and Instrumentation Frame.[5]

\section{B. Operating the wind Tunnel.}

Always use assistance when assembling the wind tunnel, some parts are heavy and are too difficult for one person to handle. Tests with the Wind Tunnel are made easier if two students work together. One student operates the fan controls and records results, while the other student monitors and adjusts the model. The steps of starting up the wind tunnel are:

- Switch on the electrical isolator on the Control and Instrumentation Frame.

- Press the red START button.

- Set the speed control to the minimum position (fully anticlockwise).

- Gradually turn the speed control clockwise until the tunnel is operating at the speed needed for the experiment. 


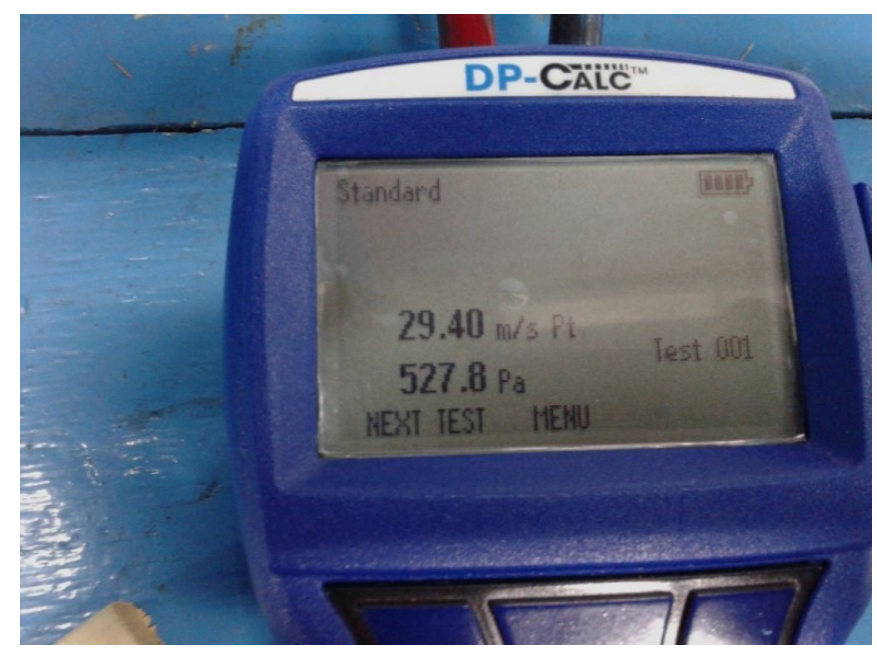

Adjustment speed

C. Steps of shutting down the machine are:

- Slowly turn the speed control fully anticlockwise.

- Press the red STOP button.

D. Steps to stop the machine in case of emergency:

- Press the red STOP button.

- Turn the speed control fully anticlockwise $20,30 \mathrm{~m} / \mathrm{s}$.

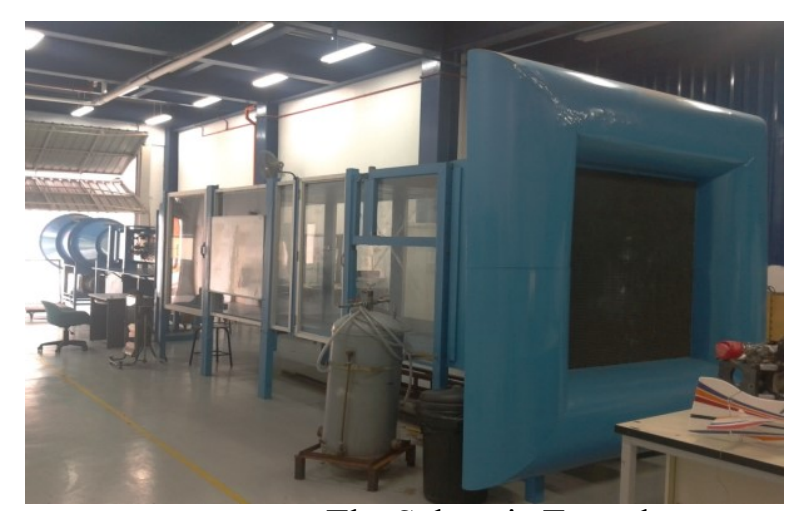

The Subsonic Tunnel

E. The steps of operation of the wind tunnel (Assembly procedure):

- Make sure that electrical supply to the Wind Tunnel is connected

- Remove the upper window.

- Tighten the Centering Clamps. From outside the Wind Tunnel, insert one of the airfoil into the collect, so that its support shaft passes into the Wind Tunnel Working Section.

- Inside the working section, measure the distance from the center of the airfoil shaft to the bottom surface of the working section.

- Close the upper window and make sure are good supported.

- Zero the manometers and take readings of the ambient air temperature.

- Connect the electrical supply to the Wind Tunnel and computer to take reading. 


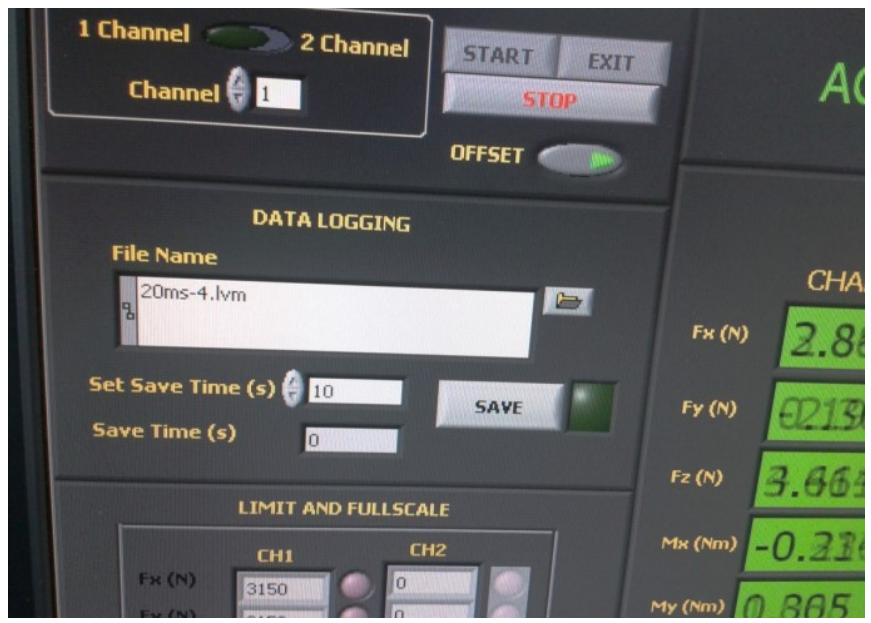

Wind tunnel reading

- Change angle of attack properly.

- Press the red START button.

- Slowly turn the speed control.

- After sport speed, take reading exactly from computer

Table1: Mach number and Reynolds number at different flow speed.

\begin{tabular}{|c|c|c|}
\hline Speed $(\mathrm{m} / \mathrm{s})$ & Mach number & Reynolds number \\
\hline $\mathbf{2 0}$ & 0.0589 & $2.0073 \times 10^{5}$ \\
\hline $\mathbf{3 0}$ & 0.0883 & $3.011 \times 10^{5}$ \\
\hline
\end{tabular}

The Mach and Reynolds numbers are calculated by the equations:

$$
\begin{aligned}
& M=\frac{V}{a}=\frac{U}{\sqrt{Y R T}} \\
& R e=\frac{\rho \in V}{\mu}
\end{aligned}
$$

F. Aerodynamic forces on aircraft

As shown in Figure there four forces acting on aircraft this forces are lift, thrust, drag weight. These forces are produced by the interaction between the aircraft and the motion of the wind. These forces contribute to the performance of the aircraft whereby it influences the aircraft in speed flight, and endurance. This forces resulting from interaction between the motion of the wind and aircraft. The lift, drag and moment are functions of attitude and configuration geometry.

Of the key factors affecting the endurance is the lift force in the plane of symmetry in the direction perpendicular to the flight line. Lift force has to be balanced by the aircraft weight for steady level flight and must has to be balanced with the aircraft weight the lift is stated as follows 


\section{$L=\frac{1}{2} \rho V^{2} S C_{L}$}

Where $\mathrm{L}$ is the lift force, $\rho$ is the air density, $\mathrm{V}$ is the air velocity, $\mathrm{S}$ is the reference area and $\mathrm{CL}$ is the lift coefficient

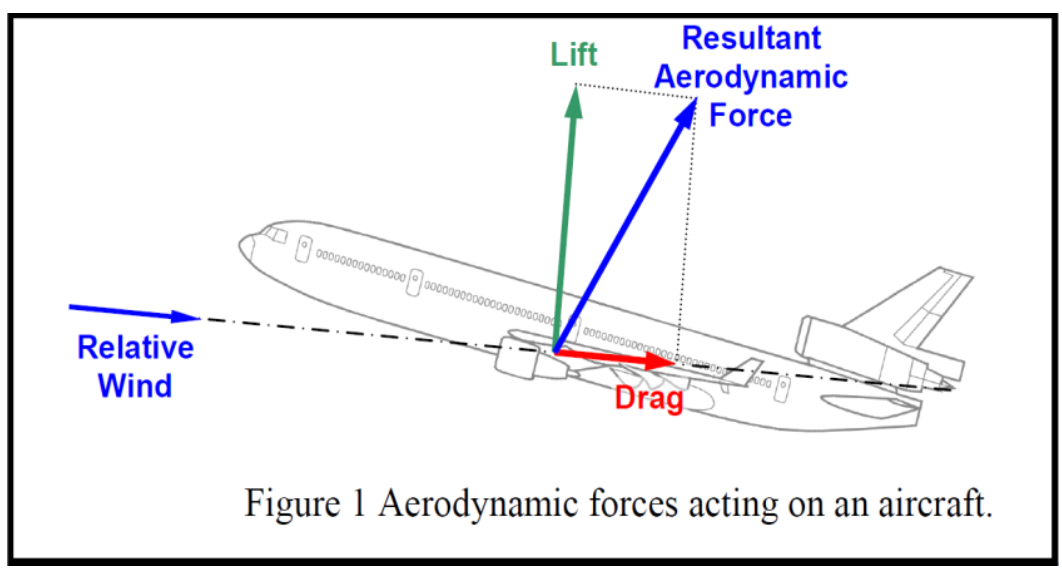

Aerodynamic forces acting on an aircraft [7]

Generation of lift is achieved by producing a greater pressure at the lower surface than upper surface of the body. The difference of the pressure is achieved when the airspeed at the upper surface is higher compared to the lower surface. Inclination of the body relative to the air flow, also contributes to the lift. Lift coefficient measures how efficiently the wing is changing velocity into lift. The higher lift coefficient indicates an efficient airfoil design. The formula of lift coefficient is:

$$
C_{E}=\frac{B}{\frac{B}{p^{2}} g}
$$

In general, drag is a force that causes a resistance in motion. It is the force developed parallel to the relative wind, and is defined as:

$$
D=\frac{1}{2} \rho V^{2} S C_{D}
$$

Where $\mathrm{D}$ is the drag force, $\rho$ is the air density, $\mathrm{V}$ is the air velocity, $\mathrm{S}$ is the reference area and $\mathrm{CD}$ is the drag coefficient. The aerodynamic drag can be defines as the sum of the tangential or skin friction force and the normal or pressure forces parallel to but in the opposite direction of the vehicle's velocity vector.

Drag is one of the important factors that affect the plane with extended region of separated flow. When the vehicle produces a lift there are drag is called induced drag. The total of form drag and skin friction is called viscous or profile drag. The drag coefficient is expressed as:

$$
C_{D}=\frac{D}{\frac{D}{g} P W^{2} S}
$$




\section{RESULTS}

This figures has been determined by wind tunnel when use FX63-137 airfoil was manufactured by $\mathrm{CNC}$ Machine and identify the best angle of attack and the best lift coefficient for each speed

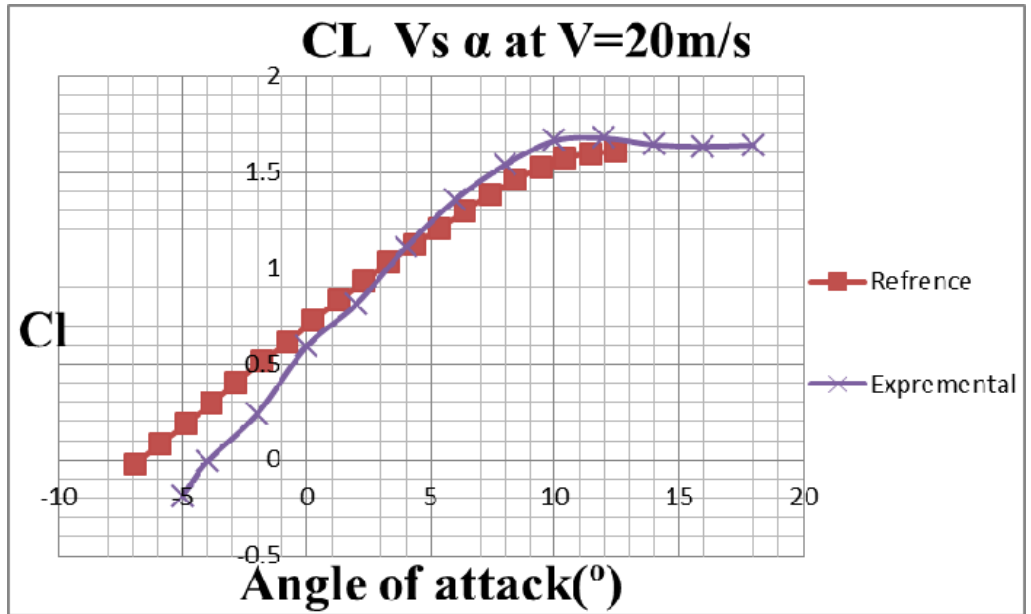

CL- $\alpha$ slope for $U=20 \mathrm{~m} / \mathrm{s}$

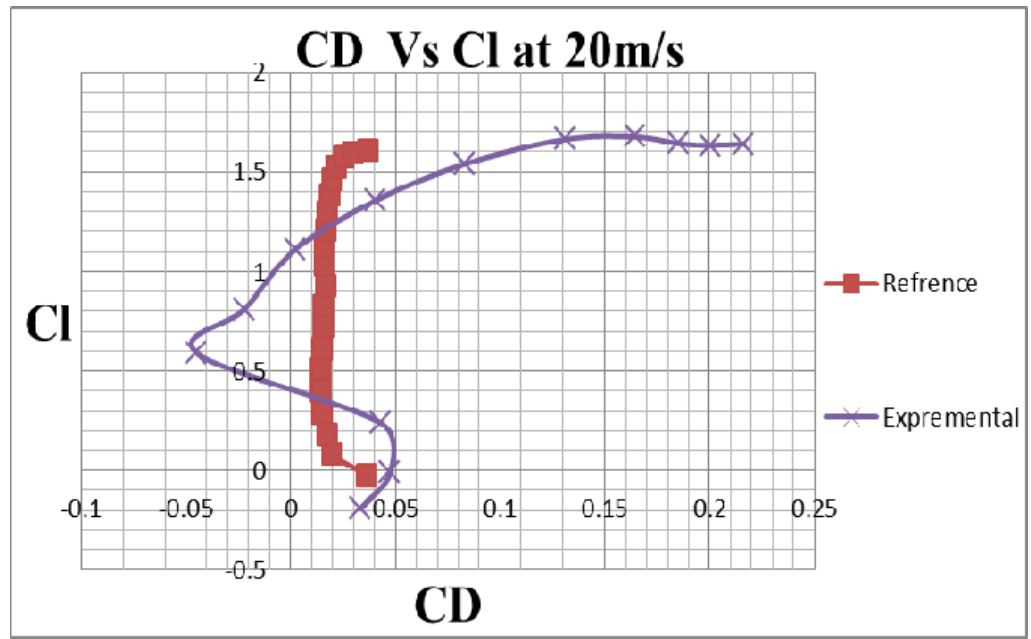

CD polar for $\mathrm{U}=20 \mathrm{~m} / \mathrm{s}$

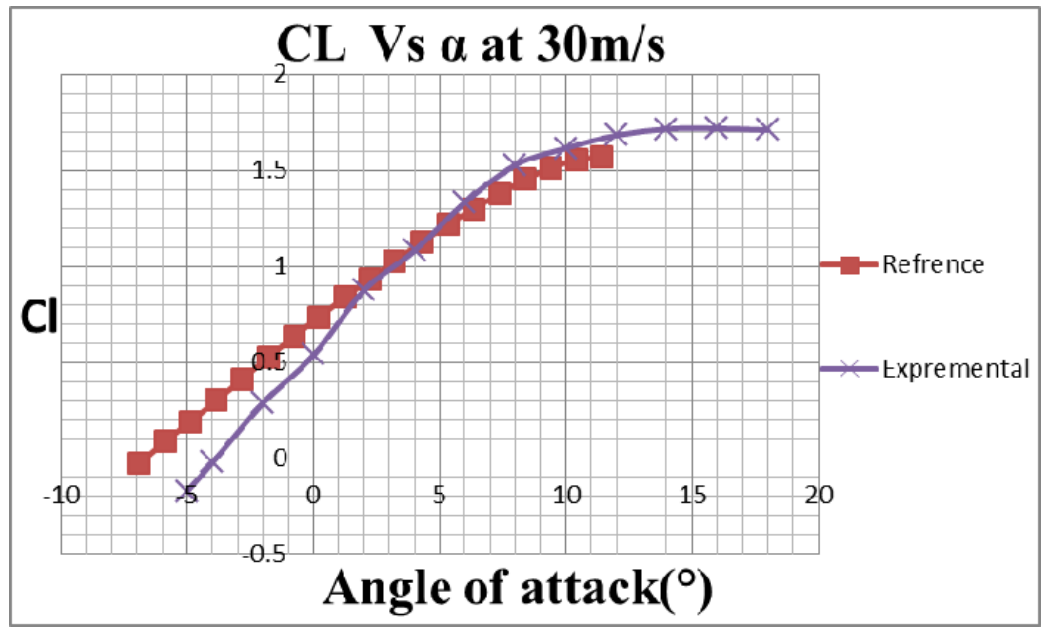

CL- $\alpha$ slope for $U=30 \mathrm{~m} / \mathrm{s}$ 


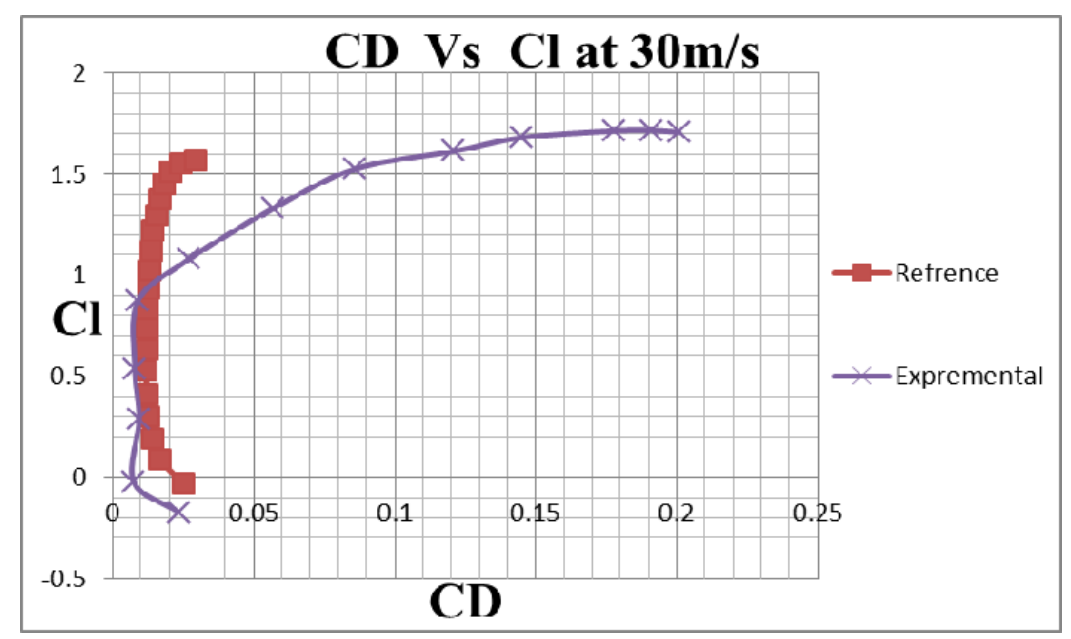

$\mathrm{CD}$ polar for $\mathrm{U}=30 \mathrm{~m} / \mathrm{s}$

Table 2. Lift and drag coefficient at different speeds

\begin{tabular}{|c|c|c|c|r|}
\hline \multirow{2}{*}{$\mathrm{A}$} & \multicolumn{2}{|c|}{$\mathrm{U}=\mathbf{2 0} \mathbf{~ m} / \mathbf{s}$} & \multicolumn{2}{c|}{$\mathbf{U}=\mathbf{3 0} \mathbf{~ m} / \mathbf{s}$} \\
& $\mathrm{Cl}$ & $\mathrm{CD}$ & $\mathrm{Cl}$ & $\mathrm{CD}$ \\
\hline $\mathbf{- 5 . 0}$ & -0.19088 & 0.03342 & -0.17166 & 0.023387 \\
\hline $\mathbf{0 . 0}$ & 0.812486 & -0.04487 & 0.536808 & 0.007768 \\
\hline $\mathbf{5 . 0}$ & 0.961426 & 0.021341 & 0.977039 & 0.042026 \\
\hline $\mathbf{8 . 0}$ & 1.539099 & 0.082932 & 1.52686 & 0.0859 \\
\hline $\mathbf{1 0 . 0}$ & 1.664822 & 0.130852 & 1.614115 & 0.121032 \\
\hline $\mathbf{1 2 . 0}$ & 1.677586 & 0.164479 & 1.681103 & 0.144787 \\
\hline $\mathbf{1 5 . 0}$ & 1.638337 & 0.192919 & 1.697675 & 0.184688 \\
\hline
\end{tabular}

\section{CONCLUSIONS}

The research presents experimental investigations of the aerodynamic characteristics of the SF63-137 airfoil at various angles of attack. It enlightens the requirements for the proper meshing of the computational domain, discusses computational aspects and presents results of the numerical study to provide insights into the airfoil aerodynamic characteristics. The problem being investigated in the present work is a low-speed case in which the flow can be considered incompressible. So, the manufacturing airfoil and good finishing is the important part to get pest result and real.

\section{References}

[1] Xin, H., Chunhua, Z., Guoqing, Z., Ping, W. \& XiChun, Z. (2012). High altitude and long endurance unmanned aerial vehicle bionic airfoil research, at. Paper read at Electronic System-Integration Technology (ESTC), 212 4th: 1568-1571. 7-20 Sept.

[2] Jianjun, Q., Yi, M. \& Mingwei, X. (2011 ). Investigation on Performance Influence of Maximum Thickness Position on Vertical Axis Wind Turbine Airfoil, at. Paper read at Power andEnergy Engineering Conference APPEE, Asia Paci c: 1-4. 2 -28.

[3] Caughey, David A. (2011). "Introduction to Aircraft, Stability and Con ol Course Notes for M\&A 5 70." 
[4] Radespiel, Rolf E., Jan Windte, and Ulrich Scholz. (2007). "Numerical and experimental flow analysis of moving."airfoils withlaminar flow and . low number AIAA journ 145.6: 1346-1356qq

[5] A. Gustafson.(2011). 'Design, Simulation, and Wind Tunnel Verification of a Morphing Airfoil'. Thesis submitted to the Faculty of the Virginia Polytechnic Institute and State University in partial.

[6] Jianjun, Q., Yi, M. \& Mingwei, X. (2011 ). Investigation on Performance Influence of Maximum Thickness Position on Vertical Axis Wind Turbine Airfoil, at. Paper read at Power and Energy Engineering Conference (APPEEC),

[7] Yang, Cher-Chiang. (2008). Low Speed Virtual Wind Tunnel Simulation For Educational Studies In Introducing Computational Fluid Dynamics And Flow Visualization.

[8] T. J. Blackwell (2011). SUBSONIC WIND-TUNNEL WALL CORRECTIONS ON A WING. Diss. San Jose

[9] Allan, Brian G., Greg S. Jones, and John C. Lin. (2011). "Simulation of a 2D Wind Tunnel Experiment." 49th AIAA Aerospace Sciences Meeting Including the New Horizons Forum and Aerospace Exposition, AIAA Paper. 